\title{
Development Coordination Disorder in Children A Parent and Teacher Guide for Early Identification (Literature Review)
}

\author{
Juel Jarani ${ }^{1}$ \\ Gentiana Nicaj \\ ${ }^{1}$ Sports University of Tirana, Faculty of Physical Activity and Rekreation, Tirana, Albania
}

\section{Doi:10.5901/ajis.2014.v3n4p203}

\section{Abstract}

The most widely internationally term used to describe children with coordination difficulties is development coordination disorder (DCD). Developmental coordination disorder is usually first recognized when a child fails to reach such normal developmental milestones as walking or beginning to dress him- or herself and is diagnosed when children do not develop normal motor coordination (coordination of movements involving the voluntary muscles). The aim of this review is to find out; the impact of development coordination disorder in children, overleaping of DCD with other conditions and finally identification and classification of children with $D C D$. Children with $D C D$ are a heterogeneous group. Any given child may present with a variety of different problems. Developmental coordination disorder $(D C D)$ is obvious when there is a marked impairment in the performance of motor skills in children. For a child with DCD, motor skills are very difficult and require more effort. The diagnosis of developmental coordination disorder is most commonly made when the child's parents or teachers notice that he or she is lagging behind peers in learning motor skills, or having learning problems in school. Identification of coordination motor difficulties (skills) is an important phase when observing children for possible development coordination disorder. These are: poor kinaesthetic acuity, poor visual perception, poor static balance and postural control, loss of information from visualspatial short-term or working memory, poor attentional control, reduced strength and enhanced co-activation of muscles, slow movement preparation, enhanced spatial and temporal variability and, finally, slow feedback processing

Keywords: children, $D C D$, overlap, classification

\section{Introduction}

Developmental coordination disorder is usually first recognized when a child fails to reach such normal developmental milestones as walking or beginning to dress him- or herself and is diagnosed when children do not develop normal motor coordination (coordination of movements involving the voluntary muscles). The symptoms of developmental coordination disorder vary greatly from child to child. Delays in motor development in young children such as sitting, crawling and walking and difficulties in self-dressing and eating may be seen.

Balance problems, clumsiness, frequent fallings and injuries may occur in pre-school periods and also incompetence in cycling, throwing and catching a ball, and difficulties in jumping and balance can be seen (Cousins and Smyth, 2003; Missiuna 2002).

The general characteristic is that the child has abnormal development of one or more types of motor skills when the child's age and intelligence quotient (IQ) are taken into account. It appears from the literature that the lower age limit of children with DCD is currently 6 years of age (Geuze et al., 2001). However, when interviewing parents of children with DCD about the natural history of their child's motor coordination problems most report these to have been present already before the child entered school (Pless et al., 2001).

Children who have developmental coordination disorder have often developed normally in all other ways. Developmental Coordination Disorder is a motor skill disorder that interferes with children's ability to perform many tasks that are required each and every day and is present mostly as impairment in locomotor, manual, and sporting skills (Wilson \& McKenzie, 1998). The disorder can, however, lead to social or academic problems for children. Deficiency in motor planning, poor motor coordination, and lack of the process in tactile, proprioceptive and kinesthetic inputs are common problems in children with DCD and they demonstrate a heavy reliance on visual feedback to guide task performance (Henderson et al., 1992; Smyth 1994). It is taught that, space visualization, position in space, space visualization and design copying parameters are affected adversely because of that reason. The aim of this review is to find out; the impact of development coordination disorder in children, overleaping of DCD with other conditions and finally 
identification and classification of children with DCD,

\section{Methods}

Regarding the procedure of finding out the literature for this review, it was used a procedure with most of databases used in the field of research

\subsection{Searching resources}

Experts in the field of development coordination disorder in children and adolescents were contacted with a view to seeking additional references.

\subsection{Electronic searches}

The search strategy was developed to be inclusive and rigorous for conducting a comprehensive search of the literature regarding development coordination disorder in children. The following databases were searched; JSTOR, Google Scholar, MEDLINE and INSPIRE. There was no exclusion regarding the age of children in this electronic database search.

\section{Results}

\subsection{Impact of DCD in children}

Children with $D C D$ are a heterogeneous group. Any given child may present with a variety of different problems. Developmental coordination disorder (DCD) is obvious when there is a marked impairment in the performance of motor skills in children. For a child with DCD, motor skills are very difficult and require more effort. The child may appear to avoid, particular activities, especially those which require a physical response, may avoid socializing with peers, particularly in physical education class or on the playground.

Comparable to their peers these difficulties have a significant impact on children's lives and their families and affect them both at home and in school.

As a consequence of these difficulties, and without adequate support and/or specific intervention within the family, school and work environments, an individual with DCD will be placed at a significant disadvantage and many children come to be expecting failure; their lower self-confidence can weaken their social and physical performance and at this children associated social and emotional problems are also common, including low self-esteem and social isolation.

Results from a study of Sigurdsson et al., (2002) show that, children with DCD have been shown to be more likely to have a higher rate of health problems than children in the general population.

It has been theorize that children with development coordination disorder may be at a risk factor for overweight and obesity problem (Cairney et al., 2005) because they have been found to be less likely to participate in physical activities (Bouffard et al., 1996). A study by Osika and Montgomery (2008), showed an increased risk of overweight or obesity over time among children with coordination problems. Findings from a study of (Cairney et al., 2010) demonstrate that children with possible developmental coordination disorder were at greater risk of overweight and obesity than children without the disorder. Results show that this risk did not diminish over the study period and concluded that developmental coordination disorder was associated not only with social, academic and emotional and behavioural problems, but also with an important risk factor for cardiovascular disease and other disease.

Missiuna in a study of 2003 describes the reasons why children have motor coordination difficulties, are awkward in movement, and have difficulty learning and performing new motor tasks, constructing an "action plan system" and explaining four possibilities:

Firstly that the child may experience difficulty interpreting and integrating the information that is being received from different senses, having difficulty choosing the type of motor action that is appropriate for that situation, having difficulty forming a plan of action in the correct sequence, and finally the message that is sent to the muscles must specify the speed, force, direction and distance that they are to be moved.

There are no known causes of developmental coordination disorder. There are, however, various theories about its 
possible causes. Some theories attribute the disorder to biological causes.

\subsection{Overlapping of $D C D$ with other conditions}

A few population-based studies have adequately controlled for confounding factors on assessment and evaluation of children with development coordination disorder, even though there is extensive literature (Kaplan et al., 2001; Hill 2001; Mari et al., 2003) describing the overlap between DCD and conditions such as attention-deficit/hyperactivity disorder, specific-language impairment (SLI), autism spectrum disorder (ASD), and dyslexia in clinic-based samples. There has been an enormous increase in the number of studies evaluating the overlap of development syndromes or disorders in children and adults

Results from different studies (Pitcher et al., 2003; Kaplan et al., 1997; Rasta and Eliot 1999) have shown an overlap of DCD with other neurodevelopment disorders and an overlap with other conditions have recently been published (Green and Baird 2005; Adib et al., 2005). Two studies from Kirby et al (2005); O'Hare and Khalid (2002), have both shown an association between motor difficulties and joint hypermobility syndrome while Green et al (2002) in their study highlighted the widespread prevalence of motor impairment in developmental disorders.

High levels of overlap of DCD with other developmental disorders are shown from a number of researchers including: ADHD, Dyslexia and ASD (Pitcher et al, 2003; Rasta and Eliot, 1999; Kaplan et al, 1997); reading, attention and motor deficits (Kooistra et al, 2005); social and emotional and behaviour, anxiety, and depression (Sigurdsson et al, 2002); speech and language impairment (Hill, 1998); and social and communication impairment (Taylor et al, 2004).

Data from a research of Kaplan et al (1997) studying Canadian population has revealed that about of $23 \%$ of children showed signs of DCD, $8 \%$ met criteria for ADHD, and 19\% were categorised as dyslexic. Nearly $25 \%$ of the affected children were found to have all three, while $10 \%$ had both ADHD and DCD, and 22\% had dyslexia and DCD.

\subsection{Identification and classification of children with $D C D$}

Diagnosis of development coordination disorder is difficult in the first year of life, but during the child growing process, while increasing motor skills performance of the child becomes more obvious to identify this disorder. The diagnosis of developmental coordination disorder is most commonly made when the child's parents or teachers notice that he or she is lagging behind peers in learning motor skills, or having learning problems in school.

Identification of coordination motor difficulties (skills) is an important phase when observing children for possible development coordination disorder. These are: poor kinaesthetic acuity, poor visual perception, poor static balance and postural control, loss of information from visual-spatial short-term or working memory, poor attentional control, reduced strength and enhanced co-activation of muscles, slow movement preparation, enhanced spatial and temporal variability and, finally, slow feedback processing (Geuze, 2005).

The phase mention together with information from parents represents a significant part of the identification of children with DCD. The information from parent of children with DCD (Pless et al., 2001) represent more functional activities of daily living such as a child's quality of performance during play, sport, locomotion, meals and dressing at preschool age. Which (combination of) signs when present at preschool age will lead to DCD is currently not known. Moreover, ways of assessing these signs reliably in early childhood is still a major challenge.

Still a number of issues surrounding the identification and definitions such as cut off points for diagnosis, who undertakes the assessment, and what type of instruments are used, surround the scientific research family. The types of motor impairment that lead to a diagnosis of developmental coordination disorder are somewhat vague, as the disorder has different symptoms in different children. There are many ways in which this kind of motor coordination problem can manifest itself, all of which may serve as criteria for a diagnosis of developmental coordination disorder. The core of the diagnosis rests on the child's being abnormally of DCD. To make this determination, the child's motor coordination must be compared to that of other children of a similar age and intelligence level.

\section{Discussion}

The most widely internationally term used to describe children with coordination difficulties is development coordination disorder (DCD). Developmental coordination disorder is usually first recognized when a child fails to reach such normal developmental milestones as walking or beginning to dress him- or herself and is diagnosed when children do not develop normal motor coordination (coordination of movements involving the voluntary muscles). The symptoms of 
developmental coordination disorder vary greatly from child to child. Children who have developmental coordination disorder have often developed normally in all other ways. In early school years DCD is strongly associated with subsequent identification of academic difficulties and psychological problems (Losse et al., 1991; Cantell et al., 1994). Characteristics of the disorder include difficulties with gross (whole body) and fine motor (using hands) skills, which may be apparent in locomotion, agility, manual dexterity, complex skills (ball games, etc), that could have significant negative effects on their ability to participate fully in the daily activities of home, school, and play as well as their social and psychological well-being (Polatajko \& Cantin, 2006). Results and conclusion from the consensus statement (Polatajko and Missiuna, 1995) showed that people with DCD display qualitative differences in movement that differentiate them from their peers without development coordination disorder. These qualitative differences change with maturity as they grow, but they tend to continue throughout life in some form.

The child with development coordination disorder may appear to avoid particular activities, especially those which require a physical response, may avoid socializing with peers, particularly in physical education class or on the playground. Comparable to their peers these difficulties have a significant impact on children's lives and their families and affect them both at home and in school. A study by Osika and Montgomery (2008), showed an increased risk of overweight or obesity over time among children with coordination problems. Findings from a study of (Cairney et al., 2010) demonstrate that children with possible developmental coordination disorder were at greater risk of overweight and obesity than children without the disorder.

No treatments are known to work for all cases of developmental coordination disorder. Many children can be effectively helped in special education settings to work more intensively on such academic problems as letter formation. For other children, physical education classes designed to improve general motor coordination, with emphasis on skills the child can use in playing with peers, can be very successful. Any kind of physical training that allows the child to safely practice motor skills and motor control may be helpful.

In conclusion not a few events show that teachers do not want to have children with disabilities/ disorder in their classrooms. Reasons that the teachers raise in these situations relate to the fact that they feel unprepared for such a job, do not have conditions, and finally do not have knowledge/ information about identification of the different condition that children may have.

\section{References}

Adib N, Davies K, Grahame R, Woo P, Murray KJ (2005). Joint hypermobility syndrome in childhood. A not so benign multisystem disorder? Rheumatology; $44: 744-50$

Bouffard M, Watkinson EJ, Thompson LP, et al (1996). A test of the activity deficit hypothesis with children with movement difficulties. Adapt Phys Activ Q; 13:61-73.

Cantell MH, Smyth MM, Ahonen T. (1994) Clumsiness in adolescence: educational, motor, and social outcomes of motor delay detected at 5 years. Adapted Physical Activity Quarterly 11: 115-29.

Cairney J, Hay JA, Faught BE, et al (2005). Developmental coordination disorder and overweight and obesity in children aged 9 to $14 \mathrm{y}$. Int J Obes (Lond);29:369-72.

Cairney, J., Hay, J., Veldhuizen, S., Missiuna, Ch., Mahlberg, N., Faught, B. E. (2010). Trajectories of relative weight and waist circumference among children with and without developmental coordination disorder. Canadian Medical Association, 182(11), 1167-1172.

Cousins, M. \& Smyth, M.M. (2003). Developmental coordination impairments in adulthood. Human Movement Science, 22.4-5, 433-459.

Hill EL (2001). Non-specific nature of specific language impairment: a review of the literature with regard to concomitant motor impairments. Int J Lang Commun Disord; 36(2):149 -171

Kaplan BJ, Crawford SG., Wilson BN, Dewey D (1997). Comorbidity of developmental coordination disorder and different types of reading disability. J Int Neuropsychol Soc;3:54

Kaplan BJ, Dewey DM, Crawford SG, Wilson BN (2001). The term comorbidity is of questionable value in reference to developmental disorders: data and theory. J Learn Disabil;34(6):555-565

Kirby A, Davies R, Bryant A (2005). Hypermobility syndrome and developmental co-ordination disorder. Int J Ther Rehab;12:431 -7

Kooistra L, Crawford S, Dewey D, Cantell M, Kaplan BJ (2005). Motor correlates of ADHD: contribution of reading disability and oppositional defiant disorder. J Learn Disabil;38:195 -206

Geuze, R.H., Jongmans, M.J., Schoemaker, M.M., \& Smits-Engelsman, B.C.M. (2001). Clinical and research diagnostic criteria for Developmental Coordination Disorder; a review and discussion. Human Movement Science, 20, 7-47.

Green D, Baird G (2005). DCD and overlapping conditions. In: Sugden DA, Chambers ME, eds. Children With Developmental Coordination Disorder. London: Whurr:93 -118

Green D, Baird G, Barnett AL, Henderson L, Huber J, Henderson SE (2002). The severity and nature of motor impairment in Asperger's syndrome: a comparison with specific developmental disorder of motor function. J Child Psychol Psychiatry;43:655 -68 
Geuze, R.H. (2005). Motor impairment in DCD and activities of daily living. In D. Sugden \& M. Chambers (Eds.), Children with Developmental Coordination Disorder (pp. 19-46). London: Whurr Publishers, Ltd.

Losse A, Henderson SE, Elliman D, Hall D, Knight E, Jongmans M. (1991) Clumsiness in children- do they grow out of it? A 10 year follow-up study. Developmental Medicine \& Child Neurology 33: 55-68.

Henderson L, Rose P, Henderson S, (1992). Reaction time and movement time in children with a Developmental Coordination Disorder. J Child Psychol Psychiatry, 33(5):895-905.

Hill EL (1998).A dyspraxic deficit in specific language impairment and developmental coordination disorder? Evidence from hand and arm movements. Dev Med Child Neurol1998;40:388 -95

Mari M, Castiello U, Marks D, Marraffa C, Prior M (2003). The reach-to-grasp movement in children with autism spectrum disorder. Philos Trans R Soc Lond B Biol Sci; 358(1430):393- 403

Missiuna. Ch (2003). Children with Developmental Coordination Disorder: At Home and in the Classroom. CanChild, Centre for Childhood Disability Research. 1-12

Missiuna C, (2002). Poor handwriting is only a symptom: children with developmental coordination disorder. Occup Ther Now,4:4-6.

O'Hare A, Khalid S (2002). The association of abnormal cerebellar function in children with developmental coordination disorder and reading difficulties. Dyslexia; $8: 234-48$

Osika W, Montgomery SM (2008). Physical control and coordination in childhood and adult obesity: longitudinal birth cohort study. $\mathrm{BMJ} ; 337: \mathrm{a699}$.

Pitcher TM, Piek JP, Hay DA. (2003). Fine and gross motor ability in males with ADHD. Dev Med Child Neurol;45:525 -35

Pless, M., Persson, K., Sundelin, C., et al. (2001). Children with Developmental Coordination Disorder: a qualitative study of parents' descriptions. Advances in Physiotherapy, 3, 128-135.

Polatajko, H. J., Fox, A.M., \& Missiuna, C. (1995). An international consensus on children with developmental coordination disorder. Canadian Journal of Occupational Therapy, 62, pp 3-6.

Polatajko H.J. \& Cantin N. (2006). Developmental coordination disorder (dyspraxia): an overview of the state of the art. Seminars in Paediatric Neurology, 12(4): 250-8.

Rasta SP, Eliot J. (1999). Written expression in boys with attention deficit hyperactivity disorder. Dev Med Child Neurol;41:159 -65

Sigurdsson E, van Os J, Fombonne E (2002). Are impaired childhood motor skills a risk factor for adolescent anxiety? Am J Psychiatry; 159:1044 -6

Smyth TR (1994). Clumsiness in children: a defect of kinaesthetic perception? Child Care Health Dev, 20(1):27-36.

Taylor E, Dopfner M, Sergeant J, et al (2004). European clinical guidelines for hyperkinetic disorder-first upgrade. Eur Child Adolesc Psychiatry 13(suppl 1):7 -30

Wilson, P.H., \& McKenzie, B.E. (1998). Information processing deficits associated with Developmental Coordination Disorder: A metaanalysis of research findings. Journal of Child Psychology and Psychiatry, 39, 829-840. 